\title{
Quantitative Analysis of Huangshui River Basin Landscape over Last Twenty Years using RS and GIS
}

\author{
Huan $\mathrm{YU}^{1, \text { a }}$, Rong-xiang $\mathrm{DU}^{1, \text { b, }}$, He-ping $\mathrm{TAO}^{2}$, Bin-tao $\mathrm{LIU}^{2}$ and Bo KONG ${ }^{2}$ \\ ${ }^{1}$ College of Earth Sciences, Chengdu University of Technology, Chengdu 610059, Sichuan, China; \\ ${ }^{2}$ Institute of Mountain Hazards and Environment, Chinese Academy of Sciences, Chengdu 610041, Sichuan, China; \\ a yuhuan0622@126.com, b1162571057@qq.com
}

\begin{abstract}
Landscape pattern change will lead to flows and changes of energy, material and nutrients between different land units, and cause sectional ecological processes and functional changes. As the political, economic, cultural and traffic center of Qinghai province, Huangshui River basin landscape structure occur significant changes under the highintensity human disturbance, so the regional environmental effects are clearly obvious. This paper obtains the dynamic change process of the main land use types in Huangshui River Basin through the techniques of RS and GIS, calculates10 types of landscape pattern indices on class level and landscape level and analyzes the landscape changes of lake, river, forest, bare soil, farm land, marsh land, grass land, industrial land and human habitation from 1990 to 2010 . The results indicate that: the landscape pattern indices have closely related with the area of land use change; landscape changed obviously in periods from 2000 to 2005; before and after 2000, the regional landscape pattern evolution characteristics showed a significant difference, the economic data collected in the basin, also confirmed this trend. 2000 years later, under the strong support of the government policy, Huangshui River basin ecological environment got continuous development, especially the grass cover and water resources.
\end{abstract}

Keywords-Huangshui River Basin; Landscape Pattern; Landscape Indices; Land Use

\section{INTRODUCTION}

Land use and land cover change (LUCC) is the result of various interactions between society and the environment [13]. As the important global environmental change component and one of the main drivers, LUCC causes tremendous changes in landscape structure, on the other hand, affects nutrient cycling and energy flow of the landscape, profound impacts the regional biodiversity and ecological processes[48]. We analyze the impact of regional land use and landscape pattern dynamic change on the ecosystem, as a scientific basis for promoting the coordinated development of regional economy and environment [9-12].

As the political, economic, cultural and transportation center of Qinghai province, Huangshui River basin has a good traffic conditions and lots of natural and artificial landscapes. Near 2/3 of the population, the most industry and agriculture of Qinghai province concentrate at this area. Huangshui River basin occupies a strategic position in the development of society and economy in the province, has a bright prospect. However, the drought, water shortage, soil erosion and serious water pollution, not only restricts the further development of the social economy, but also put forward the higher requirements for the ecological environmental protection. The conflict between the accelerating development of the social economy and the deterioration of the natural ecological environment becomes particularly obvious in the study area. It is urgent need superior and scientific approach to support the ecological environment protection and the economy and environment coordinated development.

This paper purpose: (a) to analyze landscape change and ecological response in Huangshui River basin using remote sensing and geographic information system technology, and (b) to supply new interface, thoughts and methods of regional sustainable development study, and put forward momentous decision support to the region sustainable development.

\section{STUDY AREA}

As the largest tributary of the upper area of the Yellow River, Huangshui River is located in the inter-laced zone of Qinghai Tibet Plateau and the Loess Plateau (Fig.1). The total basin area is $32900 \mathrm{~km} 2$, the elevation is $1600 \sim 4800 \mathrm{~m}$ [13]. The region is an arid, semi-arid continental climate, four seasons change obviously. The average temperature is $0.6 \sim 7.9^{\circ} \mathrm{C}$ for many years, precipitation is $360 \sim 540 \mathrm{~mm}$ (mostly in the 5 9 months), and 1100 1800mm evaporation. Sunshine hours are 2480 2920, frost free period is 68 184 day [14]. Topography of the region is complex, hilly loess gully is the main landforms and the soil erosion is serious [15]. 


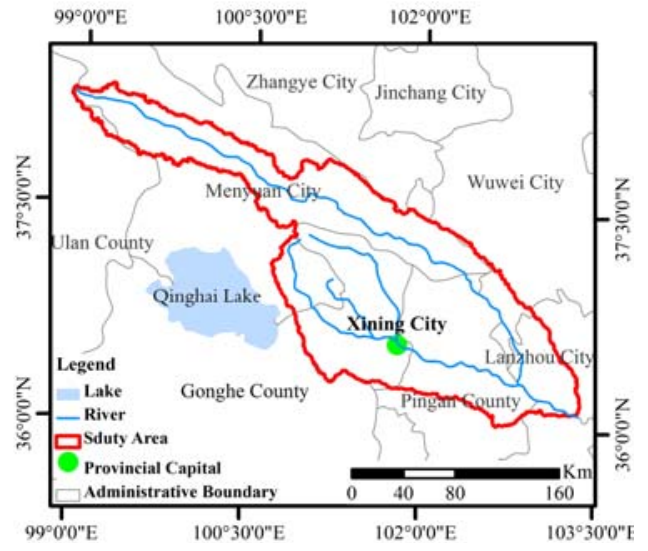

Figure 1. Location of the study area

\section{DATA AND METHODS}

This study used NASA (National Aeronautics and Space Administration) Landsat5 TM/Landsat7 ETM multi spectral remote sensing images. Five periods of remote sensing images $(1990,1995,2000,2005,2010)$ covering the study area, after the pretreatment including the radiometric correction, ortho-rectification, geometric rectification and image enhancement, were clipped and mosaicked according to the boundary of the study area. Through human-machine interactive interpretation based on Landsat TM/ETM images, the five period land-use dynamic observation data of study area were obtained. The regional landscape types are classified as: lake, river, forest, bare soil, farm land, marsh land, grass land, industrial land and human habitation. Then we used Fragstats 4.2 software to calculate the landscape index, which provided the data base for analysis of landscape temporal and spatial evolution.

Considering the research target, we choose the class-level metrics and landscape-level metrics as the primary index to represent the ecological effects. We selected the following index at the class-level metrics index: Class Area (CA), Percentage of Landscape (PLAND), Largest Patch Index (LPI), Number of Patches (NP), Patch Density (PD), and Landscape Shape Index (LSI). For the landscape-level metrics index, we selected the following index: Interspersion and Juxtaposition Index (IJI), Aggregation Index (AI), Edge Density (ED), Landscape Shape Index (LSI). The specific meaning and arithmetic of each index please view the software Fragstats 4.2 help file.

\section{RESULTS AND ANALYSIS}

\section{A. Land Use Status}

Through the interpretation of Landsat TM/ETM images, we obtained land-use dynamic observation data in study area from 1990 to 2010, and established nine landscape types including the Farm Land, Forest, Grass Land, River, Lake, Marsh Land, Human Habitation, Industrial Land and Bare Soil. Based on the land use data in each period, we calculated the landscape type area as shown in Tab.1.
TABLE I. LANDSCAPE TYPE AREA IN HUANGSHUI RIVER BASIN FROM 1990 TO 2010 (KM2)

\begin{tabular}{llllll}
\hline & $\mathbf{1 9 9 0}$ & $\mathbf{1 9 9 5}$ & $\mathbf{2 0 0 0}$ & $\mathbf{2 0 0 5}$ & $\mathbf{2 0 1 0}$ \\
\hline Marsh Land & 1627.3 & 1622.8 & 1618.8 & 1596.8 & 1595.1 \\
Bare Soil & 2376.7 & 2376.7 & 2376.6 & 2374.2 & 2369.9 \\
Farm Land & 7103.7 & 7026.9 & 6857.2 & 6545.8 & 6379.7 \\
Forest & 6469.4 & 6468.3 & 6468.0 & 6463.2 & 6460.6 \\
Grass Land & 14726.8 & 14796.3 & 14948.4 & 15234.3 & 15342.5 \\
Human Habitation & 418.7 & 429.2 & 447.7 & 481.5 & 511.0 \\
Industrial Land & 23.4 & 25.6 & 26.8 & 45.9 & 81.5 \\
Lake & 21.3 & 21.3 & 23.7 & 25.3 & 26.6 \\
River & 92.2 & 92.2 & 92.2 & 92.4 & 92.4 \\
\hline
\end{tabular}

The statistical results demonstrate that: grass land, farm land and forest are the main landscape types of Huangshui River basin, three landscape types occupy above $85 \%$ of the total basin area, grass land and farm land are the primary change types. The proportion of marsh land area in the total basin area has $5 \%$ and has a little decrease in the past 20 years; bare soil area accounts for $7.2 \%$ of the total area, decreases slowly and the variation is little; farm land area occupy about $20 \%$ of the total basin area, however, farm land reductive area accounts for $93.8 \%$ of the entire region land cover change area in the past 20 years; forest area accounts for about $20 \%$, it maintain stable quantity over the past 20 years; grass land area occupy about $45 \%$ of the study area, over the past 20 years, the increase amount of grass land area accounts for about $80 \%$ of the changed area; although accounting for $1.5 \%$ of the total basin area, the human habitation area has arose about 20\% itself in the past 20 years; industrial land only accounts for $0.25 \%$ of the total basin area, but it has increased 2.5 times from 1990 to 2010; lake area accounts for $0.08 \%$ of the total basin area and has an obvious growth over the past 20 years; river area accounts for $0.28 \%$ of the total basin area and keeps stable in the past 20 years.

\section{B. Analysis of the Class-Level Metrics Index}

Based on Fragstats 4.2 software and land use data of each period, we calculated the class-level metrics index such as NP, PD, CA, PLAND, LPI and LSI. Statistical results are shown in Fig.2.

It can be drawn from the Fig.2, the CA of marsh land is arising, which explain the marsh land area is declining in the period from 1990 to 2010; the PLAND is also decreasing, which illustrate the extent of marsh land landscape impact on the study area decreases constantly; NP has an obvious increase from 2000 to 2005, and decrease after 2005, but patch number in 2010 is still more than 1990's. The NP rising phenomenon indicates that the marsh land landscape fragmentation degree increases, NP drop-ping after 2005 shows that a lot of small patches fragmentations starts to disappear, it also shows that the marsh land ecological environment has been threaten; the PD is the same as the NP, which verifies the above mentioned conclusion; the LPI shows a decreasing trend, which also verifies the wetland 
resources have been eroded from 1990 to 2010, and the marsh land landscape influence degree in the area is reduced; the LSI increases from 1990 to 1995, shows that the marsh land landscape patch shape is more complex due to fragmentation in this period. Then, LSI starts to decline slightly from 1995 to 2010, in combination with other index, decreasing of LSI is mainly caused by some small wetland land-scape patches disappearing.

For the CA, farm land and grass land shows a significant negative correlation rule, which may indirectly explain there must be some degree of mutual transformation between both landscapes. Human habitation and industrial land shows a clear upward trend. Although lake changes is obvious, but the changes amount compared to the entire area of the study area is not obvious. As one of the main types in regional landscape, forest plays a vital role in study area. Forest landscape changes amount is little. The forest ecological environment security problem is not very serious from the perspective of landscape ecology. Bare soil and marsh land shows some degree of decline, the same change trend reflects a completely different ecological meaning. As can be seen from here, result of the ecological response caused by regional landscape pattern change is diverse. For the PLAND, we can determine the grass land, farm land, forest landscape is the main type, wetland and bare soil also occupy a considerable position, resident and industry landscape position is increase, water (rivers and lakes) in the landscape is relatively less, but taking into account the water is the core element of the ecological environment, it is regarded as the prominent landscape to analyze. For the NP and PD, the homologous landscape types performance the similar rules, human habitation has the highest number of patch and patch density, which indicates the human habitation spatial distribution is very discrete, and patch area is small relative to the other types. Grass land is 2 times the size of the forest area, but their NP and PD has little difference, this shows that the grass land spatial distribution is more concentrated than forest. Forest and farm land area is similar, but the NP and PD have obvious difference, this indicates that farm land spatial distribution is more concentrated than forest. For the LPI, farm land and grass land landscape has a larger gap with the other landscape types, which further verifies their key roles in study area. For the LSI, each landscape shows different degree changes in different periods, but it shows certain regularity that grass land is higher than the forest, forest is higher than farm land, farm land is higher than the human habitation, and human habitation is higher than bare soil, water and marsh land. Lake and industrial land landscape complexity is the lowest. This also reflects the spatial and temporal distribution of landscape types and its evolution in Huangshui River basin over the past 20 years.

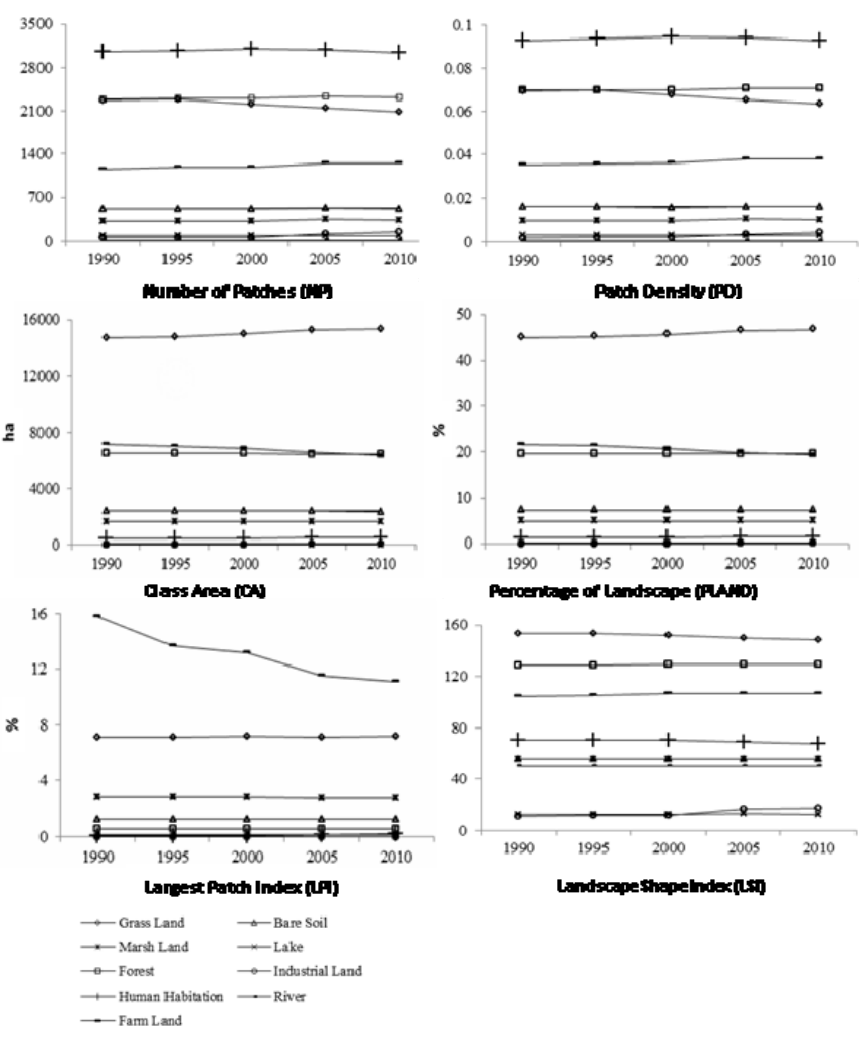

Figure 2. Class-level metrics index of the study area in different periods

\section{Analysis of the Landscape-Level Metrics Index}

Under Fragstats 4.2 software, based on land use data for each period, we calculated the Landscape-level metrics index, statistical results are shown in Fig. 3.
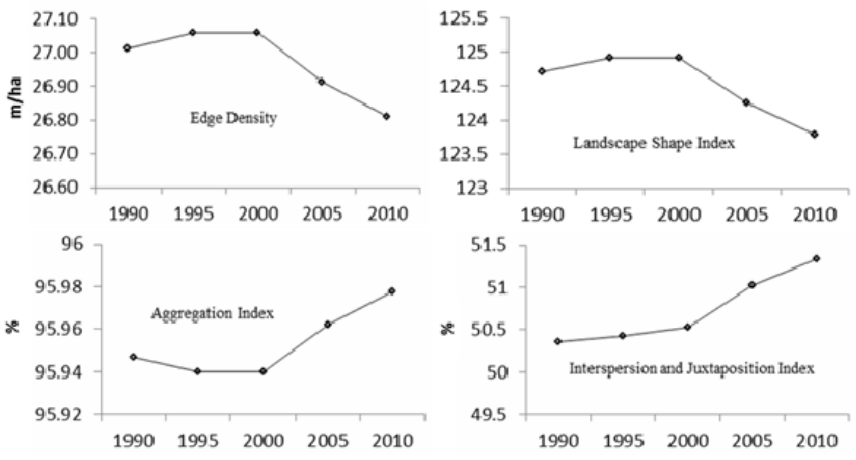

Figure 3. Landscape-level metrics indexes of the study area in different periods

The LSI and ED shows an increasing trend in the period from 1990 to 2000, which indicates the regional landscape fragmentation degree increases; the AI decreases, the landscape aggregation decreases; the IJI increases slowly, which shows that the landscape types distribution is relatively complex, mixed distribution degree between different landscape types is increased; In general, the regional landscape patch fragmentation is aggravating, the 
landscape shape and landscape spatial distribution is becoming complex. Proceed from the science of landscape ecology, the region ecological environment is gradually deterioration and have an urgent need to enhance protection measures. The ED and LSI begins to sharply reduce in the period from 2000 to 2010, which indicates that the regional landscape fragmentation is eased; AI index also begin to rise, the landscape aggregation degree is increased; the IJI rising trend shows the landscape types distribution is more complex, the regional landscape types are affected by human disturbance seriously; In general, the overall regional ecological environment is ameliorated with certain extent, but the human disturbing intensity is continuously strengthen. The ED and LSI shows the similar rule that is first increased and then decreased in the past 20 years, and the AI shows decreased first and then increased, which is a validation for the former ED and LSI indirectly. From the rule of these indices changes, the regional landscape pattern evolution characteristics showed a significant difference before and after 2000, this point has been proved in the patch type level analysis. This form of landscape changes is mainly determines by the regional development background.

\section{The Development Backgrounds of Huangshui River Basin}

Huangshui River basin is located at the junction of Loess Plateau and Qinghai Xizang Plateau, the ecological environment is very fragile; it is also the political, economic, cultural, and transportation center of Qinghai Province; with the perennial mode of economic development, the water, land, forest, grass land resources were damaged and wasted greatly, water pollution was also very serious. Since the national implementation of the western development strategy (launched in 1999), Huangshui River basin has made rapid development.

According to the Qinghai statistical yearbook data, we gained the Gross Domestic Product (GDP) and Gross Industrial Product (GIP) of districts that locates within the Huangshui River basin (Fig. 4). Results show that the basin has made great progress in the economic field especially after 2000. With the development of economy, the government adheres to comply with the basic national policy of environmental protection. 'Xining City Service Industry Environmental Protection Management Regulations', 'Qinghai Huangshui River Valley Water Pollution Prevention and Control Regulations', 'Qinghai Provincial People Government's Decision on Further Strengthening the Environmental Protection Work' and a series of environmental laws, regulations and normative documents were introduced. To grasp the chance of national western development strategy, a series of regional ecological restoration work have been launched, the regional ecological environment deterioration has been reduced to some extent.
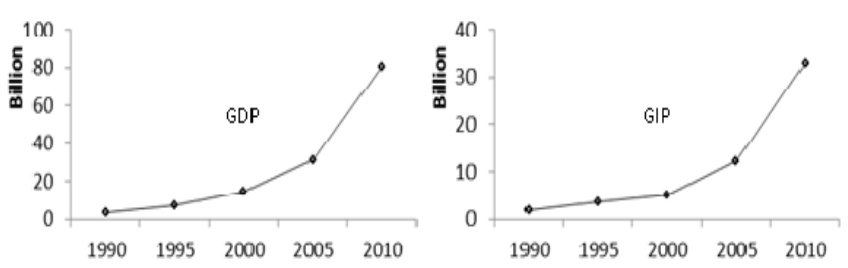

Figure 4. The study area's GDP and GIP in 1990-2010

During these 20 years, the influence of human activities on the landscape evolution has become more and more strong. On the one hand, benefited from the construction of water conservancy projects, water area has increased a lot. "Yin Da Ji Huang" project, through increased the Huangshui River Runoff and recharge the mainstream of regional groundwater, regulate the spatial allocation of river basin water resources, to effectively alleviate the severe shortage of water resources. The project of returning farm land to grass land has greatly increased the area of grass land, which effectively influences the water exchange between soil, vegetation and atmosphere. At the same time, it also kept the soil nutrient and water, and reduced the loss of soil and water. In addition, by the following Fig.5 can be seen, along with the rapid development of economy, the overall volume of wastewater discharge in Huangshui River Basin showing a growth trend, the domestic wastewater has been showing a rising trend until 2010 began to decline slightly, which is natural result of the economic development and population growth. And industrial wastewater discharge change is very interesting. Before 2009, in addition to the 2005 emissions substantially rise, other years are in decline, and later in 2009, showing a slow upward trend. This shows that the local economy is not only to develop the economy, but also to enhance the capacity of wastewater treatment to protect water resources and water environment, On the other hand, Huangshui River basin environmental improvement is closely related with human activities, which indicating that the regional ecological environment is very fragile, and the ecological system of self-adjustment and self-repair capacity is insufficient. In the era of rapid economic development, the further improvement of the Huangshui River basin ecological environment need to Qinghai Province environmental protection continue to strengthen.

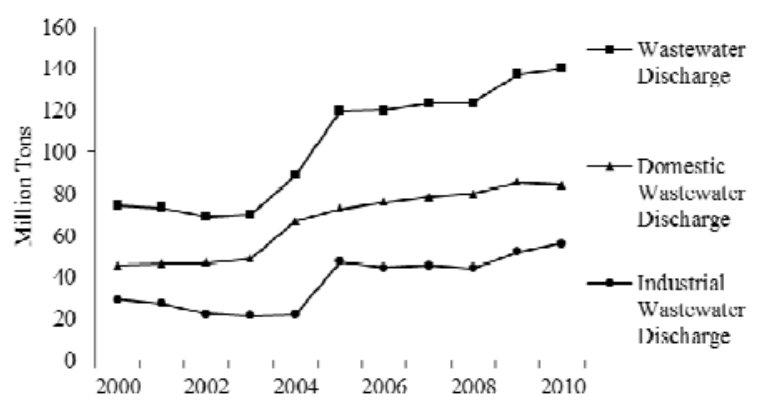

Figure 5. The study area's wastewater discharge in 2000-2010 


\section{CONCLUSIONS}

Based on the landscape changes of Huangshui River basin in past two decades, the study applies 10 types of landscape indices on class-level and landscape level, analyzes the landscape changes of lake, river, forest, bare soil, farm land, marsh land, grass land, industrial land and human habitation, then discuss the various types of spatial and temporal evolution of the landscape. The results show that farm land landscape area decreases and fragmentation increases from 1990 to 2010; due to the substantial increase in area and number of patches decrease, importance of grass land landscape in the region is more and more obvious, which is mainly benefited from a series of activities such as returning farm land to grass; forest is the main landscape type, the area continues to decrease, but the change amount is relatively small; river area keeps unchanged generally, but the lake area has been tremendous growth itself, this is the result of reservoir construction project; artificial construction landscape (human habitation, industrial land) area has been increased, and shows a tendency of concentration in the regional environment; marsh-land and bare soil landscape area reduces slightly from 1990 to 2010 and the fragmentation degree increases, which has a strong relations with the human disturbing activities such as development and construction.

The analysis results show that 2000 is not only a turning point year for economic development in the study area, but also a turning point year for the ecological environment change. After the implementation of the western development strategy, the government has increased the protection of the ecological environment and restoration efforts, which are the most immediate driving factors of regional landscape ecological evolution. Grass land and water landscape is the most important part of regional landscape evolution. Grass land area increased significantly, effectively maintaining the soil nutrients and water, land desertification situation has improved. To a certain extent, water conservancy facilities have alleviated the state of water shortage, and the effective control of wastewater discharge has reduced the water pollution. Considering the vulnerability of Huangshui River basin ecological environment, the local government should insist on saving resources and protecting the ecological environment, so as to realize the sustainable development of population, resources and environment.

\section{ACKNOWLEDGMENT}

This study is supported by the National Natural Science Foundation of China (grant no. 41101174), China Postdoctoral Science Foundation (grant no. 2013M540700), Special Grants for Postdoctoral Re-search Projects in
Sichuan Province (grant no. SZD013), Lead Strategic Project of the Chinese Academy of Sciences (grant no. XDB03030507) and Young and Middle-aged Excellent Teacher Training Program (KYGG201401).

\section{REFERENCES}

[1] Verburg, P.H.; Berkel, D.B.V.; Doorn, A.M.V. Trajectories of land use change in Europe: a model-based exploration of rural futures. Landscape Ecology, 2010, 25(2):217-232.

[2] Dıaz, G.I.; Nahuelhual, L.; Echeverrıa, C.; Marın, S. Drivers of land abandonment in Southern Chile and implications for landscape planning. Landscape and Urban Planning, 2011, 99(3-4): 207-217.

[3] Bai, J.H.; Qiong-Qiong, L.U.; Wang, J.J.; Zhao, Q.Q.; Ouyang, H.; Deng, W. Landscape pattern evolution processes of alpine wetlands and their driving factors in the Zoige Plateau of China. Journal of Mountain Science, 2013, 10(1):54-67.

[4] Zou X.P.; Qi Q.W.; Xu Z.R.; He, D.M.; Peng, X.; Jiang, L.L.; Li, J. Analysis of Land Use/ Cover Changes and Its Landscape Ecological Effects in Nujiang Watershed. Journal of Soil and Water Conservation, 2005, 19(5):147-151.

[5] Gillanders, S.; Coops, N.C.; Wulder, M.A. Multitemporal remote sensing of landscape dynamics and pattern change: describing natural and anthropogenic trends. Progress in Physical Geography, 2008, 32(5):503-528.

[6] Liu, J.; Jiang, P.; Wang, H.; Zhou, G..; Wu, J.; Yang, F. Seasonal soil $\mathrm{CO} 2$ efflux dynamics after land use change from a natural forest to Moso bamboo plantations in subtropical China. Forest Ecology \& Management, 2011, 262(6):1131-1137.

[7] Zhang, T.; Li, Y.; Chang, S.X.; Zhou, G. Responses of seasonal and diurnal soil CO2 effluxes to land-use change from paddy fields to Lei bamboo (Phyllostachys praecox) stands. Atmospheric Environment, 2013, 77(7):856-864.

[8] Dong, G.; Bai, J.; Yang, S.; Wu, L.; Cai, M.; Zhang, Y. The impact of land use and land cover change on net primary productivity on China’s Sanjiang Plain. Environmental Earth Sciences, 2015:1-11.

[9] Fan, Y.J. Study on dynamic of land use in Three Gorges reservoir area based on RS and GIS. Beijing: China. M.S. Thesis, Chinese Academy of Sciences, 2000.

[10] He, Y.S. Three Gorges project and the sustainable development. Beijing: China. Ph.D. Dissertation, Chinese Academy of Social Sciences, 2002.

[11] Ge, F.; Li, W. Review of landscape change and its ecological impacts. Ecology \& Environment, 2008, 17(6):2511-2519.

[12] Song, C.H.; Zhang, Y.; Mei, Y. Sustainability of forests created by China's Sloping Land Conversion Program: A comparison among three sites in Anhui, Hubei and Shanxi. Forest Policy \& Economics, 2014, 38(C):161-167.

[13] Bai, X.X.; Yan C.Z. Effecfs of eco-environment construction projects on soil and water loss in huangshui river basin. Bullet of Soil and Water Conservation, 2013, 33(3):217-218.

[14] Zhao C.C.; Dong. X.; Xin W.R.; Zhang F.C.; Yang X.Y. Analysis of Factors of Soil Erosion and Some Ways of Rehabilitation in Huangshui River of Qinghai Province, Research of Soil and Water Conservation, 2008,15(6):200-202.

[15] Zhao H.Q.; Li J.H. Ecological Problems and Countermeasures in Huangshui River Basin of Qinghai Province, Shandong Forestry Science and Technology, 2008, (3):75-77. 